\title{
КОРРЕКЦИОННАЯ ПЕДАГОГИКА
}

\section{ОПТИМИЗАЦИЯ ЛИЧНОСТНОГО ПОТЕНЦИАЛА РОДИТЕЛЕЙ КАК АСПЕКТ СОПРОВОЖДЕНИЯ СЕМЕЙ С ДЕТЬМИ, ИМЕЮЩИМИ НАРУШЕНИЯ ОПОРНО-ДВИГАТЕЛЬНОГО АППАРАТА}

\author{
Н. А. Дубровина \\ Уральский федеральный университет, Екатеринбург, Россия. \\ E-mail:poletaevanina@gmail.com
}

\section{Е. С. Набойченко}

Уральский государственный медииинский университет, Екатеринбург, Россия.

E-mail:dhona@mail.ru

Аннотаиия. Введение. В системе дошкольного образования родители явмяются полноправными участниками процесса воспитания. Обеспечить эффективность образовательного процесса без включения в него родителей особенно проблематично, если речь идет о ребенке младшего возраста с ограниченными возможностями здоровья (ОВЗ). Успешное психолого-педагогическое сопровождение детей с нарушениями опорно-двигательного аппарата (НОДА) вообще вряд ми возможно без участия самых близких и родных им мюдей, от психологического состояния которых и способности оказывать необходимую ребенку помощь напрямую зависит будущее растущего человека. Несмотря на это, большинство профилактических мер по социализации "особенных" детей и адаптации их в обществе не затрагивает Аичностных проблем взрослых членов их семей.

Цель публикации - представить результаты психолого-педагогического

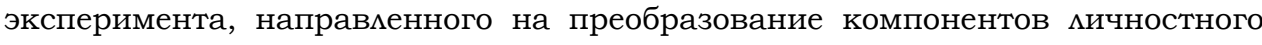
потенциала родителей дошкольников с диагнозом НОДА в период их подготовки к обучению в общеобразовательной школе.

Методология и методики исследования. В ходе исследования дия сбора эмпирических данных использовались опросник Н. П. Фетискина "Диагностика реализации потребностей в саморазвитии»; "Тест жизнестойкости" С. Мадди, адаптированный Д. А. Аеонтьевым; тест «Адаптивные стратегии поведения» Н. Н. Мельни- 
ковой; экспресс-диагностика состояния стресса К. Шрайнер. Математическая обработка полученных данных проводилась с помощью программы Statistica 12.0, с применением U-критерия Манна - Уитни и Т-критерия Вилкоксона.

Результаты и научная новизна. Выделены мотивационный, поведенческий и эмоциональный компоненты мичностного потенциала родителей, имеющих детей с НОДА. На констатирующем этапе психолого-педагогического эксперимента было установлено, что такие родители, как правило, выбирают дезадаптивные стратегии поведения. Бомьшинство из них испытывает постоянное чувство переутоммения и эмоциональное истощение, у многих слабо выражена потребность в саморазвитии. Нередко семьи, где есть дети с НОДА, находятся в ситуации стигматизации, которая заметно обостряется и усиливается на этапе подготовки к обучению в шкоме.

Дця оказания психолого-педагогической поддержки семьям, воспитывающим дошкольников с НОДА, на основе средств и методов адаптивной физической культуры разработана технология, позволяющая оптимизировать компоненты мичностного потенциала родителей и способствующая достижению оптимального уровня социально-психологической адаптированности всей семьи при поступлении ребенка в общеобразовательную школу. Апробация технологии показала значительные позитивные изменения у родителей экспериментальной группы в выборе стратегий поведения и отношения к ребенку, а также существенные положительные трансформации мотивационного и эмоционального компонентов Аичностного потенциала большей части взросмых участников эксперимента.

Практическая значимость. Полученные результаты исследования и сдеАанные авторами выводы будут весьма полезны для построения психолого-педагогической деятельности в образовательном учреждении. Внедрение в практику предлагаемого психодиагностического компцекса поможет разработать научно обоснованные методики и рекомендации взаимодействия педагогов и психологов с взрослыми чиенами семьи ребенка с НОДА на этапе его подготовки к школе.

Ключевые слова: нарушения опорно-двигательного аппарата (НОДА), Аичностный потенциал, дошкольный возраст, стратегии поведения, родители, мотивационный компонент, поведенческий компонент, эмоциональный компонент.

Благодарности. Авторы признательны рецензентам журнала "Образование и наука" за помощь в подготовке статьи.

для иитирования: Дубровина Н. А., Набойченко Е. С. Оптимизация Аичностного потенциала родителей как аспект сопровождения семей с детьми с нарушениями опорно-двигательного аппарата // Образование и наука. 2018. T. 20, № 8. C. 129-147. DOI: 10.17853/1994-5639-2018-8-129-147 
Оптимизаиия личностного потенииала родителей

как аспект сопровождения семей с детьми,

имеюшими нарушения опорно-двигательного аппарата

\title{
THE OPTIMISATION OF PARENTING PERSONAL POTENTIAL AS AN ASPECT OF SUPPORT FOR FAMILIES OF CHILDREN WITH MOVEMENT DISORDERS
}

\author{
N. A. Dubrovina \\ Ural Federal University named after the first President of Russia B. N. Yeltsin, \\ Yekaterinburg, Russia. \\ E-mail:poletaevanina@gmail.com
}

\section{E. S. Naboichenko}

Ural State Medical University, Ekaterinburg, Russia. E-mail:dhona@mail.ru

Abstract. Introduction. In the system of preschool education, parents are full participants of the learning process. It is highly problematic to provide the efficiency of the educational process without involving parents, especially, in the case of younger children with special healthcare needs (CSHCN). Successful psychological and pedagogical guidance to children with movement disorders is hardly possible without the participation of the closest people. The future of children directly depends on the psychological state of their parents and their ability to provide the necessary assistance. Nevertheless, the majority of preventive measures intended for the socialisation of "special" children and their adaptation in the society does not affect the personal issues of adult family members.

The aim of the research was to present the results of psychological and pedagogical experiment directed to the transformative components of personal potential of parents of preschool children with movement disorders during their preparation for education at the comprehensive school.

Methodology and research methods. In the course of the research, the following psychological approaches were used: the questionnaire developed by N. P. Fetiskin "Diagnostics of realisation of the needs for self-development"; S. Maddi's Hardiness Survey adapted by D. A. Leontiev; N. N. Melnikova's Adaptive Behavior Strategies questionnaire; K. Shreiner's Express Diagnostics of the Stress Level. Mathematical processing of empirical data was carried out using the software statistica 12.0 with the application of the Mann-Whitney U-test and the Wilcoxon T-test.

Results and scientific novelty. The motivational, behavioural and emotional components of personal potential in parents of children with movement disorders were identified. In the course of the first stage of the research, it was revealed that parents of children with movement disorders choose disadaptive behavioural strategies. The majority of parents experience a constant fatigue and stress, the need for self-development is on the low level. Frequently, families of children with mo-

Образование и наука. Том 20, № 8. 2018/The Education and Science Journal. Vol. 20, № 8. 2018 
vement disorders are in the situation of stigmatisation that considerably becomes aggravated and amplifies at the stage of preparation for schooling.

The developed technology of the psychological and pedagogical support for families will allow optimising components of parenting personal potential and achieving an optimal level of the family social and psychological adaptability when preparing children for entry into schools. The approbation of technology showed considerable positive changes in the parents of experimental group when choosing the strategy of behaviour and attitude towards their children. Moreover, essential positive transformations of motivational and emotional components of personal potentials were identified in the majority of adult participants.

Practical significance. The findings obtained and the conclusions drawn by the authors will be very useful to designing psychological and pedagogical activity in educational institutions. The implementation into practice of the proposed psycho-diagnostic complex will help to develop evidence-based approaches and recommendations for the interaction of educational institutions with adult members of families of children with movement disorders at the stage of preparation for school.

Keywords: movement disorders, personal potential, preschool children, behavioral strategies, parents, motivational component, behavioural component, emotional component.

Acknowledgements. The authors express their deep gratitude to the reviewers of the Education and Science Journal for their help in preparing the present paper.

For citation: Dubrovina N. A., Naboichenko E. S. The optimisation of parenting personal potential as an aspect of support for families of children with movement disorders. The Education and Science Journal. 2018; 8 (20): 129-147. DOI: DOI: 10.17853/1994-5639-2018-8-129-147

\section{Введение}

В последние годы в России принимаются энергичные меры дия интеграции киц с ограниченными возможностями здоровья (ОВЗ) в общество. Прежде всего, большое внимание уделяется инклюзивным программам обучения и воспитания детей с разАичными психофизическими статусами.

Непременным условием процесса включения детей данной категории в социокуцьтурную среду является обеспечение их взаимодействия с микросоциумом. При этом невозможно игнорировать тот факт, что в силу детского возраста и особых потребностей дошкольников с ОВЗ полноправными участниками этого процесса становятся родители. От психологического состояния посмедних и их способности оказывать необходимую помощь ребенку напрямую зависит будущее растущего челове-

Образование и наука. Том 20, № 8. 2018/The Education and Science Journal. Vol. 20, № 8. 2018 
Оптимизаиия личностного потенииала родителей

как аспект сопровождения семей с детьми

имеюшими нарушения опорно-двигательного аппарата

ка. Несмотря на это, большинство мер по социализации "особенных" детей не затрагивает мичностных пробцем их родителей.

Отклонения в развитии традиционно воспринимаются обществом как ненормативные, что опредемяет неоднозначное, часто негативное, впцоть до стигматизации, отношение к мицам с ОВЗ.

По данным $\Lambda$. В. Шапковой, наибольшее неприятие со стороны социума ощущают родители детей с нарушениями опорно-двигатемьного аппарата (НОДА) [1]. В отмичие, например, от патологий атипичной внешности НОДА в большинстве случаев не операбельны и более заметны окружающим, чем иные патологические недуги. Ситуация осложнятся еще и тем, что физическим отк^онениям разАичной степени при НОДА могут сопутствовать другие патомогии.

Особым событием в жизни семей с нетипичными детьми становится период интеграции в систему школьного образования, который нередко сопровождается обострением стигматизации и появлением новых проблем.

С целью оказания поддержки в решении данных проблем нами быма разработана технология психолого-педагогического сопровождения семей, имеющих детей дошкольного возраста с НОДА, в которой были задействованы средства и методы адаптивной физической культуры.

В статье представцены результаты эксперимента, направценного на преобразование компонентов мичностного потенциала родителей детей с НОДА. В ходе апробации технологии были выявлены также особенности детско-родительских отношений в дошкольный период детства, однако в данной публикации мы ограничимся только анализом данных, характеризующих динамику психологических изменений родителей на этом этапе.

\section{Обзор Аитературы}

Вопросы воспитания и обучения детей с НОДА рассматриваются в таких областях науки, как специальная психология, дефектология, коррекционная педагогика, адаптивная физическая культура, поскольку абимитация таких детей, несомненно, носит междисциплинарный характер.

Результаты исследования А. В. Смирнова показали, что физические недуги одного из членов семьи приводят к ощущению неполноценности у других. Существует несколько неблагополучных сценариев семейного развития. Некоторые родители сознательно скрывают от общества факт рождения ребенка с НОДА. Другие, напротив, пытаются получить от сложившихся обстоятельств своеобразную "выгоду" в виде размичных материальных пособий и мьгот. Во многих семьях практикуется гиперопека, которая приводит к самоизоляции не только ребенка, но и всей семьи [2]. 
По фактам, установленным Н. Г. Уэстрайхом, воспитание детей с НОДА по типу гиперопеки в сочетании с недостатком требований и запретов осуществцяется в $75 \%$ случаев $^{1}$.

Вместе с тем, как отмечает В. В. Ткачева, в семьях с такими детьми может иметь место и эмоциональное отвержение ребенка, которое порой проявляется в жестоком обращении [3].

Е. В. Устинова попыталась выявить и сформулировать причины негармоничного воспитания и искажения детско-родительских отношений в семьях дошкольников с особенностями развития. К ним относятся:

- воспитательная неуверенность родителей (90\% семей);

- страх за здоровье ребенка (60\%);

- повышенный уровень тревожности (93\% матерей и 60\% отцов);

- эмоциональное соотнесение личности ребенка с понятиями "тревога" $(56 \%)$ и "болезнь" (36\%);

- эмоционально-отрицательное отношение к понятиям "материнство" $(6,7 \%)$ и "Отцовство" (36\%);

- неустойчивость воспитательной тактики в семье (20\%);

- чувство вины перед ребенком (60\%);

- предпочтение "инфантилизации" в процессе воспитания ребенка $(60 \%)[4]$.

По мнению А. С. Спиваковской, в семьях, где воспитывается ребенок с НОДА, ярко выражена эмоциональная неустойчивость, "сиюминутность внутрисемейных отношений". Всё, что происходит в подобной семье, связано в основном с текущими "сегодняшними" проблемами жизни ребенка, тогда как процесс воспитания детей с нормативным развитием иной: в "обычных" семьях его характеризуют адекватность, "прогностичность в оценках происходящего", направленность на будущее ${ }^{2}$.

В исследованиях зарубежных авторов фиксируется четкая связь между восприятием ребенка чменами семьи и ее адаптационными возможностями. При этом отмечается, что стресс в большей степени проявляется у матерей, которые демонстрируют низкую самооценку, усугубляющуюся материальной зависимостью от супругов [5].

В ходе изучения процесса формирования сотрудничества в семьях с детьми с НОДА было выявлено, что отношение к ребенку обусловливают особенности его коммуникативного поведения [6].

1 Уэстрайх Н. Г. Основные методы физической реабилитации больных с двигательными нарушениями. Минск: Беморусская ассоциация помощи детяминвалидам "Открытые двери", 1997. 195 с.

2 Спиваковская А. С. Как быть родителями. Москва: Педагогика, 1986. 160 с.

Образование и наука. Том 20, № 8. 2018/The Education and Science Journal. Vol. 20, № 8. 2018 
Оптимизаиия личностного потенииала родителей

как аспект сопровождения семей с детьми,

имеюшими нарушения опорно-двигательного аппарата

У многих родителей отмечается неумение создавать ситуации совместной деятемьности, несформированность потребности в общении, неэмоциональное и неадекватное взаимодействие, неуверенность в воспитательных мерах и отсутствие чувствительности по отношению к ребенку, порой до полного отказа от него [7].

Как уже говорицось выше, семьи, воспитывающие детей с НОДА, зачастую находятся в ситуации стигматизации, которая обостряется на этапе подготовки к школе. В этот период, с одной стороны, возникает опасность деструктуризации семьи, с другой - появцяются затруднения ее социальной адаптации и интеграции в общество. Особые потребности развития, вызванные нарушениями опорно-двигательного аппарата, в усмовиях массового образовательного учреждения становятся более заметными. Несмотря на сохранность интемлекта, период перехода на школьную ступень образования у детей с такими нарушениями может оказаться более диительным, чем у их сверстников, развивающихся в соответствии с физиологической нормой.

С приближением начала обучения ребенка с НОДА в школе происходят трансформации мичностного потенциала его родителей. При неблагоприятном развитии событий проблема родительской педагогической безграмотности осложняется социально-психологической изоляцией семьи. Ограничение возможностей взаимодействия с окружающим социумом вызывает эмоциональную нестабильность в решении повседневных задач обучения и воспитания детей, снижает мотивацию к социальному взаимодействию и в конечном счете приводит к дезадаптивным стратегиям поведения.

Вместе с тем, исходя из выводов, сделанных Д. А. Аеонтьевым, иичностный потенциал позволяет запускать саморегуляционные механизмы в изменяющихся внешних условиях, т. е. мичность может не только оставаться устойчивой к проявлениям извне, адекватно реагировать на изменения как внутренней, так и внешней ситуации, но и вносить изменения во внешний мир ${ }^{1}$

Убежденность специалистов в необходимости психомого-педагогической работы с родителями основана, прежде всего, на представлении о том, что семья - это структура, обладающая потенциальными возможностями создания благоприятных условий дмя развития и воспитания ребенка $[6,8,9]$.

Дия детей с НОДА основополагающим предметом является адаптивная физическая культура, поскольку именно на таких занятиях формиру-

1 Аеонтьев Д. А. Деятельность. Сознание. Аичность. Москва: Политиздат, 1975. 304 с. Образование и наука. Том 20, № 8. 2018/The Education and Science Journal. Vol. 20, № 8. 2018 
ются двигательные навыки ребенка, уменьшается или увеличивается тонус мышц, развиваются навыки самообслуживания $[10,11]$.

Однако правильный двигательный режим для такого ребенка на этапе подготовки $\mathrm{k}$ школе не должен начинаться и заканчиваться в спортивном зале. Необходимо, чтобы его соблюдали все чиены семьи дошкольника [12]. Поэтому мы разработали специальную технологию обучения родителей детей с НОДА, в которой используются средства и методы адаптивной физической культуры.

Семья и педагоги должны работать как команда, как единый механизм. Именно в этом и состоит основная идея предмагаемой технологии психолого-педагогического сопровождения семей, имеющих детей дошкольного возраста с НОДА.

\section{Материамы и методы иссиедования}

Предметом нашего изучения стали психологические особенности семей, имеющих детей с НОДА и сохранным интемлектом, и пути их социально-психологической адаптации на этапе подготовки школе. Изучение данной проблемы имеет комплексный фундаментальный характер и относится к области педагогической психомогии.

М. А. Акопян, исследуя необходимость педагогической поддержки семей, выделила следующие компоненты мичностного потенциала родителей:

- познавательные;

- ценностно-смысловые;

- поведенческие возможности [13].

Однако в семьях с детьми с НОДА феномен родительства часто искажается ввиду длительного влияния стрессовых факторов в связи с рождением ребенка с особыми потребностями и заботами о его состоянии и удовлетворении его нужд. На наш взгляд, в таких семьях мичностный потенциал родителей раскрывается в трех компонентах:

- мотивационном - выражается в желании родителей быть успешными в достижении цемей;

- эмоциональном - представлен в понимании родителями признаков эмоционального комфорта и напряжения;

- поведенческом - характеризуется позицией родителя (активной или пассивной) в вопросах воспитания, обучения и развития ребенка с НОДА.

Мы не выделяем отдельно когнитивный компонент Аичностного потенциала родителей, поскольку он рассматривается как неотъемлемая часть всех остальных компонентов. В мотивационном компоненте когнитивная составляющая представмена в виде осознания потребности к са- 
Оптимизаиия личностного потенииала родителей

как аспект сопровождения семей с детьми,

имеюшими нарушения опорно-двигательного аппарата

моразвитию, в эмоциональном - как знание родителей об имеющихся возможностях для достижения эмоционального комфорта, в поведенческом как общий уровень жизнестойкости в условиях стихийно складывающегося формирующего пространства.

Разработанная нами технология психолого-педагогического сопровождения содержит три блока: психологический, педагогический и адаптивный.

Педагогический блок включает занятия дмя чменов семьи адаптивной физической культурой в диадах "педагог - ребенок", "родитель - ребенок", консультации и беседы; проведение совместных праздников и спортивных эстафет. Основная цель данных мероприятий - обучить родителей применять средства адаптивной физической культуры дмя двигатемьного развития детей с НОДА.

Психомогический блок направлен на коррекцию детско-родительских отношений и оптимизацию компонентов мичностного потенциала. В него включены применение диагностических методик для исследования мичностного потенциала родителей и детско-родительских отношений, проведение психологических тренингов.

Предназначение адаптивного блока заключается в составлении индивидуальной программы двигательного развития ребенка с НОДА, который готовится стать первоклассником. В ходе занятий родители учатся проводить мониторинг формирования двигательных навыков и навыков самообслуживания у детей, а также следовать рекомендациям, указанным в индивидуальных программах.

Общая цель реализации технологии - социально-психологическая адаптация семьи, имеющей ребенка дошкольного возраста с НОДА, путем использования средств и методов адаптивной физической культуры.

В ходе достижения данной цели решаются следующие задачи:

1) определение степени соответствия условий, в которых растет и воспитывается ребенок дома, требованиям его уровня развития;

2) выявление внутрисемейных факторов, как способствующих, так и препятствующих гармоничному развитию ребенка с НОДА в семье;

3) опредемение причин, дестабилизирующих внутрисемейную атмосферу и межличностные отношения родителей с ребенком;

4) опредемение путей гармонизации внутрисемейного климата;

5) опредемение путей социально-психологической адаптации как детей с НОДА, так и их семей на этапе подготовки к школе;

6) адаптация домашних усмовий под нужды ребенка с НОДА;

7) обеспечение двигательного развития ребенка с НОДА на этапе подготовки к шкоме.

Образование и наука. Том 20, № 8. 2018/The Education and Science Journal. Vol. 20, № 8. 2018 
Все мероприятия технологии направлены на получение единого результата - обеспечение социально-психологической адаптированности семьи и ребенка дошкольного возраста с НОДА.

В качестве диагностических методик в ходе исследования и апробации технологии были использованы:

1) опросник Н. П. Фетискина "Диагностика реализации потребностей в саморазвитии" [14], который определяет особенности мотивационного компонента Аичностного потенциала родителей детей с НОДА;

2) “Тест жизнестойкости" С. Мадди, адаптированный Д. А. Аеонтьевым [15], диагностирующий вовлеченность, контроль, принятие риска, что составляет поведенческий компонент Аичностного потенциала родителей;

3) тест "Адаптивные стратегии поведения" Н. Н. Мельниковой [16], фиксирующий поведенческие стратегии в проблемных ситуациях (поведенческий компонент Аичностного потенциала родителей);

4) экспресс-диагностика состояния стресса К. Шрайнер [17], определяющая уровень развития эмоционального компонента Аичностного потенциала родителей;

5) тест-опросник родительского отношения А. Я. Варги и В. В. Столина, диагностирующий особенности детско-родительских отношений [18];

6) мониторинг формирования двигательных навыков, который позволяет оценить развитие двигательных навыков у детей с НОДА по семи группам показатемей [19];

7) карта оценки навыков самообслуживания, определяющая уровень сформированности необходимых навыков самообслуживания (гигиена, прием пищи, одевание) [20].

Экспериментальной базой исследования был клуб по месту жительства "Надежда", входящий в состав МБУДО "ДЮЦ «Вариант" г. Екатеринбурга (далее - клуб "Надежда»). В исследовании приняли участие дети дошкольного возраста с НОДА (122 человека), имевшие сохранный интелмект, и сопровождавшие их родители (116 матерей и 6 отцов) - всего 244 человека. Гендерные признаки в исследовании не учитывались. Участники были разделены на две группы: экспериментальную (62 ребенка и их родители) и контрольную (60 детей и их родители).

Все родители явмялись неработающими, поскольку основной деятельностью каждого из них было сопровождение ребенка с НОДА. В экспериментальной группе из 62 семей 24 явмялись неполными (воспитание осуществляма мама, чаще всего при поддержке ее родителей), 38 - полными. В контрольной группе из 60 семей 26 являлись неполными, 34 - полными. 
Оптимизаиия личностного потенииала родителей

как аспект сопровождения семей с детьми

имеюшими нарушения опорно-двигательного аппарата

Нарушения опорно-двигатемьного аппарата детей обеих групп классифицировались как средние и мегкие.

Аегкие нарушения характеризуются возможностью самостоятельного передвижения, но с замедленным темпом и неловкостью движений. У детей нарушена координация, замедлена реакция, снижены амплитуда и активность движений в суставах, нарушен мышечный тонус, имеется асимметрия развития конечностей. Негативное влияние на развитие навыков самообслуживания оказывают нарушения манипулятивной функции рук.

Средняя степень НОДА означает наличие способности удерживать самостоятельно вертикальную стойку, однако характеризуется ограничением навыков самообслуживания вследствие нарушений мышечного тонуса и координации, возможным наличием гиперкинетических движений. Самостоятельная ходьба находится на стадии формирования, т. е. чаще всего осуществляется с помощью технических средств (ходунков, тростей, костылей) или за руку с сопровождающими.

Дети, участвовавшие в психолого-педагогическом эксперименте, посещали детские сады с инклюзивными формами обучения, включающими групповые занятия с музыкальным руководителем, инструктором по физической культуре и воспитателем. Помимо детского сада многие дошкольники занимались индивидуально (платно) со специалистами по адаптивной физической культуре и могопедом. Как правимо, такие занятия носили курсовой характер, т. е. не были регулярными.

Несмотря на разнообразие занятий дмя детей в обеих группах, планомерного психолого-педагогического сопровождения родителей не осуществлялось ни в одном образовательном учреждении. Работа с родителями проводимась, но имела массовый и информативный характер (родительские собрания, информационный стенд). Родители могми обратиться за помощью к специалистам, однако эти консультации носили "стихийный", одномоментный характер. Таким образом, специалисты постоянно взаимодействовали преимущественно с детьми.

В ходе нашего исследования родителям и детям экспериментальной группы было предможено принять участие в комплексе мероприятий, предусмотренных технологией психолого-педагогического сопровождения семей, имеющих детей дошкольного возраста с НОДА.

Основная цель данной статьи - освещение процесса оптимизации мичностного потенциала родителей и результатов применения разработанной для решения этой задачи технологии. При обработке промежуточных и итоговых данных использовались такие математические методы, как U-критерий Манна - Уитни и Т-критерий Вилкоксона, а также программа STATISTICA 12.0 .

Образование и наука. Том 20, № 8. 2018/The Education and Science Journal. Vol. 20, № 8. 2018 


\section{Резумьтаты исследования}

На констатирующем этапе психолого-педагогического эксперимента результаты контрольной и экспериментальной групп были проверены на отсутствие размичий (табл. 1).

Таблица 1

Проверка различий переменных контрольной и экспериментальной групп с применением непараметрического U-критерия Манна - Уитни

Table 1

Verification of differences in the variables of control and experimental groups using the Mann - Whitney U-test

\begin{tabular}{|l|c|}
\hline \multicolumn{1}{|c|}{ Переменные } & Уровень значимости, $\mathrm{p}$ \\
\hline \multicolumn{2}{|c|}{ Мотивационный компонент личностного потенциала родителей } \\
\hline Потребность в саморазвитии & 0,844 \\
\hline Поведенческий компонент личностного потенциала родителей \\
\hline Вовлеченность & 0,876 \\
\hline Принятие риска & 0,920 \\
\hline Контроль & 0,920 \\
\hline Жизнестойкость & 0,900 \\
\hline Стратегии поведения & 0,647 \\
\hline Поведенческий компонент (общий показатемь) & 0,920 \\
\hline Эмоциональный Компонент личностного потенииала родителей \\
\hline Стресс & 0,498 \\
\hline Личностный потенциал (общий показатемь) & 0,840 \\
\hline
\end{tabular}

Анализ мичностного потенциала родителей обеих групп до эксперимента выявиц низкий уровень выраженности мотивационного компонента, что проявлямось в стагнации развития (рисунок).

Большинство родителей (57\%), участвующих в эксперименте, постоянно испытывали переутомление и эмоциональное истощение, что связано, прежде всего, с ситуацией стихийно складывающегося формирующего пространства, в которой находятся родители после рождения ребенка с НОДА.

Тест жизнестойкости выявиц средние показатели вовлеченности, контроля и принятия риска (поведенческий компонент Аичностного потенциала) у родителей обеих групп. Поясним: средний уровень жизнестойкости способствует возникновению внутренней напряженности в стрессовых ситуациях.

Поведенческий компонент наиболее отчетливо был представлен в выборе стратегий поведения, которые характеризовались в основном как дезадаптивные. Чаще всего родители обеих групп выбирали следующие стратегии поведения:

- уход от контакта со средой и погружение во внутренний мир (100\% респондентов);

Образование и наука. Том 20, № 8. 2018/The Education and Science Journal. Vol. 20, № 8. 2018 
Оптимизаиия личностного потенииала родителей

как аспект сопровождения семей с детьми,

имеюшими нарушения опорно-двигательного аппарата

- пассивное выжидание внешних изменений (100\%);

- пассивное подчинение условиям среды $(94,3 \%)$;

- уход из среды и поиск новой $(90,3 \%)$

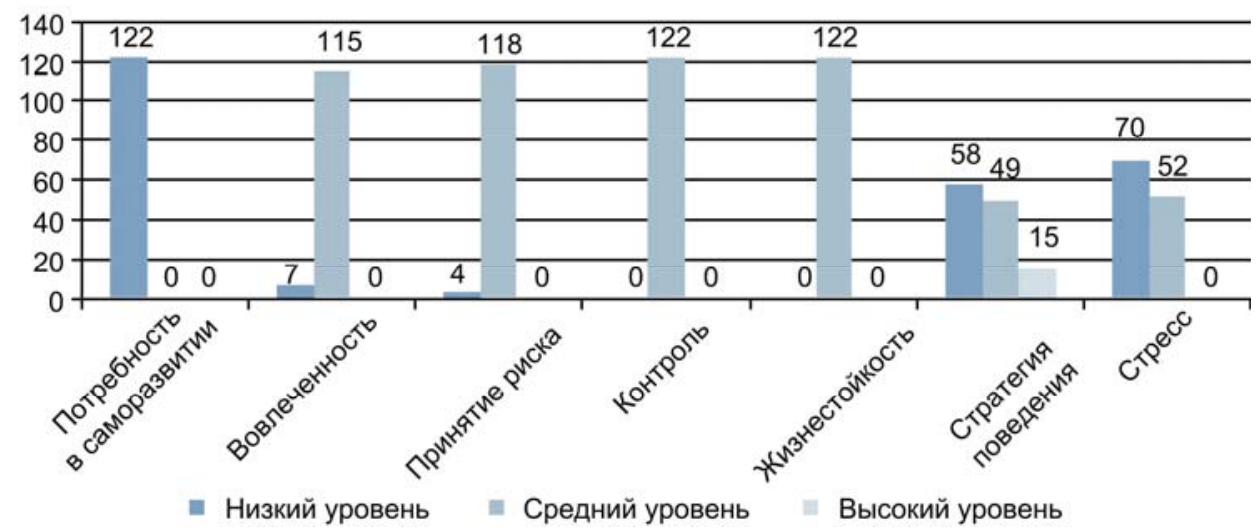

Уровни выраженности компонентов Аичностного потенциала родителей обеих групп до участия в эксперименте (количество человек, $n=122$ ) Levels of expression of the components of parenting personal potentials in both groups prior to participation in the experiment (number of people, $n=122$ )

Перечисленные стратегии в наибольшей степени способствуют формированию социальной самоизоляции.

После участия в комплексной практической апробации технологии психомого-педагогического сопровождения у 48 родителей (78\%) экспериментальной группы были зафиксированы конструктивные изменения в выборе адаптивных стратегий поведения, т. е. большинство испытуемых освоици новые позитивные поведенческие стратегии, например "Активное изменение среды". Однако у 14 (22\%) позитивной динамики, к сожалению, обнаружено не бымо.

Кроме того, итогом проделанной работы стали положительные приращения по шкалам теста жизнестойкости. Высокие балмы по шкале "вовмеченность" в экспериментальной группе после психолого-педагогического эксперимента показывают, что у родителей вырос интерес к процессу обучения и воспитания ребенка с НОДА, они стали получать больше положительных эмоций от качественной целенаправленной деятельности.

УАучшения по шкале "Контроль" означают, что родители осознали способность управцять ситуацией, а не «плыть по течению".

Диагностика по шкале "Принятие риска" выявияа расширение возможностей родителей. Они стали осуществцять больше практических дей- 
ствий, понимая, что отрицательные и положительные результаты - это важные составляющие опыта.

Общий результат жизнестойкости соответственно также улучшился, что свидетельствует о положительных изменениях поведенческого компонента мичностного потенциала в силу возросшего уровня компетентности родителей в вопросах обучения и воспитания детей с НОДА.

В результате применения технологии выявцены положительные изменения мотивационного компонента цичностного потенциала родителей экспериментальной группы:

- 11 человек (18\%) стали активно реализовывать свои потребности в саморазвитии;

- 51 (82\%) продемонстрировали саморазвитие.

Повторная диагностика состояния стресса выявила качественные изменения эмоционального компонента мичностного потенциала родитемей экспериментальной группы. Тестирование до участия в исследовании показало состояние переутомления и истощения, после - способность бомее адекватно реагировать на стрессовые факторы и улучшение психоэмоционального фона.

Дия определения степени влияния технологии на мичностный потенциал родителей экспериментальной группы был использован Т-критерий Виккоксона (сравнение "до" и "после») и обнаружены позитивные сдвиги по всем переменным, что свидетельствует о положительном воздействии на участников психолого-педагогического эксперимента (табл. 2).

Табиица 2

Наличие изменений в результатах контрольной и экспериментальной групп после применения технологии с использованием Т-критерия Вилкоксона

Table 2

Changes in the results of control and experimental groups after using the technology with the Wilcoxon T-test application

\begin{tabular}{|c|c|c|}
\hline \multirow[b]{2}{*}{ Переменные } & \multicolumn{2}{|c|}{ Уровень значимости, $\mathrm{p}$} \\
\hline & $\begin{array}{c}\text { Экспериментальная } \\
\text { группа }\end{array}$ & Контрольная группа \\
\hline 1 & 2 & 3 \\
\hline \multicolumn{3}{|c|}{ Мотиваиионный компонент } \\
\hline Потребность в саморазвитии & $0,000^{*}$ & 0,739 \\
\hline \multicolumn{3}{|c|}{ Эмоииональный компонент } \\
\hline Стресс & 0,000 & 0,739 \\
\hline \multicolumn{3}{|c|}{ Поведенческий компонент } \\
\hline Вовлеченность & 0,000 & 0,132 \\
\hline
\end{tabular}

Образование и наука. Том 20, № 8. 2018/The Education and Science Journal. Vol. 20, № 8. 2018 
Оптимизаиия личностного потенииала родителей

как аспект сопровождения семей с детьми

имеюшими нарушения опорно-двигательного аппарата

\begin{tabular}{|l|c|c|}
\hline \multicolumn{1}{|c|}{1} & 2 & 3 \\
\hline Контроль & $\mathbf{0 , 0 0 0}$ & 0,366 \\
\hline Принятие риска & $\mathbf{0 , 0 0 0}$ & 0,172 \\
\hline Жизнестойкость & $\mathbf{0 , 0 0 0}$ & $\boldsymbol{0 , 0 2 3}$ \\
\hline Изменение среды & $\mathbf{0 , 0 0 0}$ & 0,157 \\
\hline Изменение себя & $\mathbf{0 , 0 0 0}$ & 1,000 \\
\hline Уход из среды & $\mathbf{0 , 0 0 0}$ & 1,000 \\
\hline Погружение в себя & $\mathbf{0 , 0 0 0}$ & 0,157 \\
\hline Пассивная презентация & $\mathbf{0 , 0 2 9}$ & 0,157 \\
\hline Пассивное подчинение & $\mathbf{0 , 0 0 1}$ & 0,180 \\
\hline Пассивное выжидание & $\mathbf{0 , 0 0 0}$ & 0,581 \\
\hline
\end{tabular}

Примечание. Полужирным начертанием выделен статистически достоверный сдвиг.

Несмотря на то, что в контрольной группе по всем методикам практически не выявцено изменений, проверка результатов на наличие сдвига посредством Т-критерия Вилкоксона показала улучшение по переменной "Жизнестойкость". Согласно программе STATISTICA 12.0, изменения зафиксированы у 25 из 60 родителей данной группы.

\section{Обсуждение и закиючение}

Представценные в статье данные раскрывают один из аспектов применения технологии психолого-педагогического сопровождения семей, имеющих детей дошкольного возраста с НОДА, - преобразование компонентов мичностного потенциала родителей.

Результаты исследования показали, что родители детей с НОДА нуждаются в психолого-педагогическом сопровождении не меньше, чем их дети. Комплексная помощь таким семьям способствует не только адаптации и нормализации нарушенных функций детей с НОДА, но и раскрытию потенциальных возможностей их родителей. Это открывает членам всей семьи "выход" из самоизоляции, в которой она оказалась ввиду психотравмирующих обстоятельств и социальной стигматизации.

Проведенное исследование доказывает необходимость рассматривать семью с ребенком с НОДА как автономную систему, где все компоненты имеют последовательные и прочные связи. Позитивные сдвиги, увеличивающие эффективность процесса интеграции в общество семей с "особенными" детьми, происходят, если работа по психолого-педагогическому сопровождению осуществцяется одновременно по трем направлениям: дети - родители - детско-родительские отношения.

Полученные в ходе эксперимента результаты требуют дальнейшего рассмотрения в контексте изучения стиця детско-родительских отноше- 
ний в семьях с детьми с НОДА и развитием навыков детей. Однако этот вопрос будет освещен в смедующих публикациях.

\section{Список использованных источников}

1. Шапкова $\Lambda$. В. Частные методики адаптивной физической культуры: учебное пособие. Москва: Советский спорт, 2004. 464 с.

2. Смирнов А. В. Самоизоляция мичности в критической жизненной ситуации физической инвалидности. Екатеринбург: Уральский государственный педагогический университет, 2004. 142 с.

3. Ткачева В. В. Семья ребенка с отклонениями в развитии: диагностика и консультирование. Москва: Книголюб, 2008. 144 с.

4. Устинова Е. В. Преодоление эмоциональных нарушений у дошкольников с церебральным параличом в процессе оптимизации их отношений с родитемями // Дефектология. 2005. № 1. С. 52-57.

5. Manuel J., Naughton M. J., Balkrishnan R., Smith B., Koman L. A. Stress and adaptation in mothers of children with cerebral palsy / / Journal of Pediatric Psychology. 2003. № 28 (3). P. 197-201.

6. Набойченко Е. С. Семья как социально-психологический аттрактор формирования дезадаптации у детей школьного возраста с атипичной внешностью // Педагогическое образование в России. 2012. № 2. С. 55-57.

7. Tracy L. J., Ronald J. Prinz Potential roles of parental self-efficacy in parent and child adjustment // Clinical Psychology Review. 2005. Vol. 25, issue 3. P. 341-363.

8. Овчарова Р. В. Родительство как психологический феномен: учебное пособие. Москва: Московский психолого-социальный институт, 2006. 496 с.

9. Ткачева В. В. Технологии психологической помощи семьям детей с отклонениями в развитии: учебное пособие. Москва: АСТ; Астрель, 2007. 318 с.

10. Chiarello L. A., Palisano R. J., Maggs J. M., Orlin M. N., Almasri N., Kang L. J., et al. Family priorities for activity and participation of children and youth with cerebral palsy // Physical Therapy. 2010. Sep; Vol. 90 (9). P. 1254-1264.

11. Murphy N. A., Carbone P. S. Promoting the participation of children with disabilities in sports, recreation, and physical activities // American Academy of Pediatrics Council on Children with Disabilities. Pediatrics. 2008 May; Vol. 121 (5). P. 1057-1061.

12. Kang L. J., Palisano R. J., King G. A., Chiarello L. A. A multidimensional model of optimal participation of children with physical disabilities // Disability and Rehabilitation. 2014. Vol. 36 (20). P. 1735-1741.

13. Акопян М. А. Роль семейного воспитания в становмении мичности // Современные проблемы психологии семьи: феномены, методы, концепции. Вып. 2. С.-Петербург: ИПП, 2008. С. 9-15.

14. Фетискин Н. П., Козмов В. В., Мануйлов Г. М. Социально-психологическая диагностика развития мичности и малых групп. Москва: Институт психотерапии, 2002. 490 с. 
Оптимизаиия личностного потенииала родителей

как аспект сопровождения семей с детьми,

имеюшими нарушения опорно-двигательного аппарата

15. Аеонтьев Д. А., Рассказова Е. И. Тест жизнестойкости. Москва: Смысл, 2006. 63 c.

16. Мельникова Н. Н. Диагностика социально-психологической адаптации мичности: учебное пособие. Челябинск: ЮУрГУ, 2004. 57 с.

17. Дмитриев М. Г., Белов В. Г., П Парфенов Ю. А. Психомого-педагогическая диагностика делинквентного поведения у трудных подростков. С.-Петербург: ПОНИ, 2010. 316 с.

18. Немов Р. С. Психология: учебник дия студентов высших педагогических учебных заведений: в 3 кн. 4-е изд. Кн. 3: Психодиагностика. Введение в научное психологическое исследование с элементами математической статистики. Москва: ВААДОС, 2001. 640 с.

19. Топоркова Н. А. Мониторинг формирования двигательных навыков детей дошкольного возраста с детским церебральным параличом // Адаптивная физическая культура: ежеквартальный журнал. С.-Петербург. 2012. № 3 (51). С. 24-25.

20. Полетаева Н. А., Серова Н. Б. Педагогическое сопровождение семей как средство реабилитации детей дошкольного возраста с ДЦП // Развитие технологий здоровьесбережения в современном обществе: материалы международной студенческой научно-практической конференции. Екатеринбург, 3-4 июня 2015 г. Екатеринбург: Уральский университет, 2015. С. 143-162.

\section{References}

1. Shapkova L. V. Chastnye metodiki adaptivnoj fizicheskoj kul'tury = Private methods of adaptive physical training. Moscow: Publishing House Soviet Sport; 2004. 464 p. (In Russ.)

2. Smirnov A. V. Samoizoljacija lichnosti v kriticheskoj zhiznennoj situacii fizicheskoj invalidnosti $=$ Self-isolation of a person in a critical life situation of physical disability. Ekaterinburg: Ural State Pedagogical University; 2004. 142 p. (In Russ.)

3. Tkacheva V. V. Sem’ja rebenka s otklonenijami v razvitii: diagnostika i konsul'-tirovanie $=$ Family of a child with developmental disabilities: Diagnosis and counselling. Moscow: Publishing House Knigolyub; 2008. 144 p. (In Russ.)

4. Ustinova E. V. Overcoming of emotional disorders in preschool children with cerebral palsy in the process of optimisation of their relations with parents. Defektologiya $=$ Defectology. 2005; 1: 52-57. (In Russ.)

5. Manuel J, Naughton M. J, Balkrishnan R, Smith B, Koman L. A. Stress and adaptation in mothers of children with cerebral palsy. Journal of Pediatric Psychology. 28 (3); 2003: 197-201.

6. Naboichenko E. S. Family as a socio-psychological attractor of the formation of disadaptation in school-age children with atypical appearance. Pedagogicheskoe obrazovanie $v$ Rossii = Pedagogical Education in Russia. 2012; 2: 55-57. (In Russ.)

7. Tracy L. J., Prinz R. J. Potential roles of parental self-efficacy in parent and child adjustment: A review. Clinical Psychology Review. 2005. 25, 3: 341-363.

8. Ovcharova R. V. Roditel'stvo kak psihologicheskij fenomen = Parenthood as a psychological phenomenon. Moscow: Moscow Psychological and Social Institute; 2006. 496 p. (In Russ.)

Образование и наука. Том 20, № 8. 2018/The Education and Science Journal. Vol. 20, № 8. 2018 
9. Tkacheva V. V. Tehnologii psihologicheskoj pomoshhi sem'jam detej s otklonenijami $\mathrm{v}$ razvitii $=$ Technologies of psychological assistance to families of children with developmental disabilities. Moscow: Publishing Houses AST; Astrel; 2007. 318 p. (In Russ.)

10. Chiarello L. A., Palisano R. J., Maggs J. M., Orlin M. N., Almasri N., Kang L. J., et al. Family priorities for activity and participation of children and youth with cerebral palsy. Physical Therapy. 2010 Sep; 90 (9): 1254-1264.

11. Murphy N. A., Carbone P. S. Promoting the participation of children with disabilities in sports, recreation, and physical activities. American Academy of Pediatrics Council on Children with Disabilities. Pediatrics. 2008 May; 121 (5): 1057-1061.

12. Kang L. J., Palisano R. J., King G. A., Chiarello L. A. A multidimensional model of optimal participation of children with physical disabilities. Disability and Rehabilitation. 2014; 36 (20): 1735-1741.

13. Akopyan M. A. Rol' semejnogo vospitanija v stanovlenii lichnosti = The role of family education in the formation of personality. Sovremennye problemy psihologii sem'i: fenomeny, metody, koncepcii = Modern problems of family psychology: Phenomena, methods, concepts. Iss. 2. St.-Petersburg: Publishing House IPP; 2008. p. 9-15. (In Russ.)

14. Fetiskin N. P., Kozlov V. V., Manuylov G. M. Social'no-psihologicheskaja diagnostika razvitija lichnosti i malyh grupp = Socio-psychological diagnosis of personality development and small groups. Moscow: Institute of Psychotherapy; 2002. 490 p. (In Russ.)

15. Leontiev D. A., Rasskazova E. I. Test zhiznestojkosti = Test of resilience. Moscow: Publishing House Smysl; 2006. 63 p. (In Russ.)

16. Melnikova N. N. Diagnostika social'no-psihologicheskoj adaptacii lichnosti $=$ Diagnostics of the socio-psychological adaptation of an individual. Chelyabinsk: South Ural State University; 2004. 57 p. (In Russ.)

17. Dmitriev M. G., Belov V. G., Parfenov Yu. A. Psihologo-pedagogicheskaja diagno-stika delinkventnogo povedenija u trudnyh podrostkov = Psychological and pedagogical diagnosis of delinquent behaviour in difficult adolescents. St.-Petersburg: Publishing House PONI; 2010. 316 p. (In Russ.)

18. Nemov R. S. Psihologija = Psychology. In 3 books. 4th ed. Kn. 3: Psihodiagnostika. Vvedenie $\mathrm{v}$ nauchnoe psihologicheskoe issledovanie $\mathrm{s}$ jelementami matematicheskoj statistiki $=$ Book 3: Psychodiagnostics. Introduction to scientific psychological research with the elements of mathematical statistics. Moscow: Publishing House VLADOS; 2001. 640 p. (In Russ.)

19. Toporkova N. A. Monitoring the formation of motor skills of preschool children with infantile cerebral palsy. Adaptivnaya fizicheskaya kul'tura = Adaptive Physical Culture. 2012; 3 (51): 24-25. (In Russ.)

20. Poletaeva N. A., Serova N. B. Pedagogical support of families as a means of rehabilitation of children of preschool age with cerebral palsy. In: Razvitie tehnologij zdorov'esberezhenija $v$ sovremennom obshhestve: materialy mezhdunarodnoj studencheskoj nauchno-prakticheskoj konferencii. Ekaterinburg, 3-4 ijunja 2015 g. = Development of Health Saving Technologies in Modern Society. Materials

Образование и наука. Том 20, № 8. 2018/The Education and Science Journal. Vol. 20, № 8. 2018 
Оптимизаиия личностного потенииала родителей

как аспект сопровождения семей с детьми,

имеюшими нарушения опорно-двигательного аппарата

of the International Student Scientific and Practical Conference; 2015 Jun 3-4; Ekaterinburg. Ekaterinburg: Ural University; 2015. p. 143-162. (In Russ.)

\section{Информаиия об авторах:}

Дубровина Нина Амександровна - аспирант Уральского федерального университета им. первого Президента России Б. Н. Ельцина, старший преподаватель Института физической культуры, спорта и молодежной политики Уральского федерального университета им. Б. Н. ЕАьцина, Екатеринбург, Россия. E-mail: poletaevanina@gmail.com

Набойченко Евгения Сергеевна - профессор, доктор психологических наук, заведующая кафедрой клинической психологии, декан факультета психолого-социальной работы и высшего сестринского образования Уральского государственного медицинского университета, Екатеринбург, Россия. E-mail: dhona@mail.ru

Вклад соавторов в исследование равный.

Статья поступила в редакцию 21.04.2018; принята в печать 15.08.2018. Авторы прочитали и одобрили окончательный вариант рукописи.

\section{Information about the authors:}

Nina A. Dubrovina - Post Graduate Student, Senior Lecturer, Institute of Physical Culture, Sports and Youth Policy, Ural Federal University named after the first President of Russia B. N. Yeltsin, Ekaterinburg, Russia. E-mail: poletaevanina@gmail.com

Evgenia S. Naboichenko -4 Professor, Doctor of Psychological Sciences, Head of the Department of Clinical Psychology, Dean of the Faculty of Psycho-Social Work and Higher Nursing Education, Ural State Medical University, Ekaterinburg, Russia. E-mail: dhona@mail.ru

Contribution of the authors. Both authors contributed equally to this research.

Received 21.04.2018; accepted for publication 15.08.2018.

The authors have read and approved the final manuscript. 